\title{
¿Qué significa hoy la idea de autonomía para la Biología?*
}

\author{
What Does the Idea of Autonomy Mean Today for Biology?
}

Alvaro Moreno ${ }^{\dagger \ddagger}$

\begin{abstract}
Resumen
Desde Darwin, la biología se ha articulado sobre la idea de evolución por selección natural, que ha influido profundamente en la comprensión científica y filosófica de los fenómenos biológicos y de nuestro lugar en la naturaleza. En este trabajo se argumenta por qué la biología actual debe avanzar hacia a una idea aún más fundamental, la de autonomía. La idea de autonomía recoge el hecho de que los organismos vivos son sistemas autoorganizados, capaces de auto-producción y auto-mantenimiento, que se constituyen como entidades integradas para establecer sus propios objetivos y normas, y promueven las condiciones de su existencia a través de sus interacciones con el entorno. Sin embargo, hasta ahora la idea de autonomía biológica se ha entendido más bien como autosuficiencia y en tensión con las formas de organización colectivas. Argumentaré que debemos desarrollar, por el contrario, una idea de autonomía en complementariedad con éstas, constatando la importancia y ubicuidad de los procesos de colaboración y simbiosis, que, lejos de constituir una objeción a la tesis aquí defendida, requieren para ser entendidos precisamente de la idea de autonomía.
\end{abstract}

Palabras clave: autonomía - cierre de constricciones - función - interacción - identidad

\begin{abstract}
Ever since Darwin, biology has been based on the idea of evolution through natural selection, and this in turn has deeply influenced our scientific and philosophical understanding of biological phenomena and our place in nature. This work explores why modern-day biology should advance towards an even more fundamental idea, namely that of autonomy. The idea of autonomy reflects the fact that living organisms are self-organized systems capable of selfproduction and self-maintenance, which establish themselves as integrated entities in order to set out their own objectives and rules and foster the conditions necessary for their existence through their interactions with the environment. Nevertheless, to date, the idea of biological autonomy has been understood more as self-sufficiency, something in tension with collective forms of organization. In contrast to this view, I will argue that we should develop an idea of autonomy that complements these collective forms, recognizing the importance and ubiquity of collaboration and symbiosis which, far from opposing the thesis defended here, require the very idea of autonomy in order to be properly understood.
\end{abstract}

Keywords: autonomy - closure of constraints - function - interaction - identity

* Recibido: 19 de Julio de 2016. Aceptado con revisiones: 5 de Diciembre de 2016.

† Departamento de Lógica y Filosofía de la Ciencia, Universidad del País Vasco. Para contactar al autor, por favor, escribir a: alvaro.moreno@ehu.es.

* El autor agradece la ayuda del Proyecto de Subvención de Grupos del Gobierno Vasco, IT 590-13, y del MINECO, FFI2014-52173-P. También a los organizadores del II Congreso de la Asociación Iberoamericana de Filosofía de la Biología (AIFIBI), llevado a cabo en Valle de Bravo, México, en Septiembre de 2015.

Metatheoria 8(1)(2017): 157-168. ISSN 1853-2322.

(C) Editorial de la Universidad Nacional de Tres de Febrero. Publicado en la República Argentina. 


\section{Introducción}

Si tuviésemos que expresar en pocas palabras qué es lo que caracteriza al fenómeno de la vida, seguramente aludiríamos a la enorme plasticidad, robustez y fuerza, a las mil maneras de manifestarse, adaptarse y de recuperarse frente a condiciones adversas. Todas estas propiedades vienen manifestándose en la superficie de nuestro planeta casi desde que éste presentó las condiciones adecuadas para el surgimiento de la vida. Por eso, nos hemos acostumbrado a ver la vida como un fenómeno casi "ordinario". Sin embargo, desde una perspectiva más global, la vida es un fenómeno absolutamente extraordinario. En un breve lapso de tiempo en términos de la historia del cosmos, un conjunto de moléculas -es decir, de estructuras insignificantemente pequeñas- se organizan en alguna pequeñísima parte del universo (posiblemente en varias partes y en tiempos distintos) formando un vasto sistema integrado que ha ido ampliándose, tanto espacial como temporalmente.

Nuestro conocimiento de este extraordinario fenómeno ha progresado en los últimos 100 años también de manera no menos impresionante: seguramente son las Ciencias de la Vida la rama del conocimiento científico que ha experimentado un desarrollo más rápido y espectacular. Sin embargo, este desarrollo adolece de una estructura conceptual capaz de organizar y unificar no sólo el enorme caudal de información empírica disponible, sino las numerosas teorías locales -a veces incompatibles entre sí, y en todo caso, inconexas- que tratan de ordenar esa información empírica (ecología, genética de poblaciones, biología del desarrollo, etc.). Y precisamente uno de los problemas más importantes que plantea este objetivo de unificación es encontrar una forma inteligible de ordenar esta compleja fenomenología. Quizás para muchos biólogos esto no se plantee como un problema, pensando que al fin y al cabo, la Teoría de la Evolución por Selección Natural proporciona las claves esenciales para entender de un modo coherente la complejidad de lo viviente. Pero esta es una creencia ingenua.

Es verdad que, como bien decía Dobzhansky (1973), "nada tiene sentido en Biología sin la evolución"; pero no es menos cierto que la propia evolución presupone la existencia de esas entidades individualizadas que la Biología tradicional ha denominado "organismos". De hecho, la Teoría de la Evolución por Selección Natural no explica el funcionamiento de los organismos, ni permite tampoco explicar la demarcación entre lo vivo y lo no-vivo. En este sentido, la teoría evolutiva no puede pretender ser la base para unificar las ciencias de la vida. Si intentamos entender la impresionante capacidad de la vida para proliferar, para crear una enorme variedad de formas, y en particular, para actuar en y modificar los diferentes entornos, nuestra atención deberá dirigirse a las entidades vivientes individuales, cuya fundamental expresión son los organismos (y cuya forma mínima es la célula).

Una visión del mundo biológico centrada en el organismo es fundamental porque sólo si somos capaces de definir un sistema bien delimitado e individualizado de relaciones podremos explicar la aparición de nuevas capacidades biológicas. Como señalara Varela:

[The] evolutionary thought, through its emphasis on diversity, reproduction, and the species in order to explain the dynamics of change, has obscured the necessity of looking at the autonomous nature of living units for the understanding of biological phenomenology. Also I think that the maintenance of identity and the invariance of defining relations in the living unities are at the base of all possible ontogenetic and evolutionary transformation in biological systems (Varela 1979, p. 5).

Y aunque es cierto que desde su aparición los organismos han tendido a asociarse y a constituir sistemas colectivos de los más variados tipos, sólo si somos capaces de establecer formas de individualidad podremos definir dónde operan las fuerzas selectivas, explicar el desarrollo de la agencialidad y especificar los sistemas desde los que surgen las interacciones ecológicas. 


\title{
2. La organización de los organismos
}

Desde este planteamiento, pues, la cuestión que surge es: ¿cuál es el núcleo fundamental de la organización de los organismos? Hace dos siglos Kant ([1790] 1981) respondía a esta pregunta así:

\begin{abstract}
En semejante producto de la naturaleza, del mismo modo que cada parte existe sólo mediante las demás, también ha de ser pensada como existiendo en orden a las demás y al todo, esto es, como instrumento (órgano). Lo cual, sin embargo, no es suficiente [...], sino que ha de ser pensada como órgano productor de las otras partes (por consiguiente, cada una productora de las demás, recíprocamente), tal como no puede serlo ningún instrumento del arte [ningún artefacto o máquina, por ejemplo un reloj, donde cada una de las partes están en función de las demás, pero ninguna es producida por otra, pues la idea del todo procede de fuera], sino sólo de la naturaleza, la cual proporciona la materialidad para todos los instrumentos [...]. Y sólo entonces y por eso, semejante producto, en cuanto ser organizado y que se organiza a sí mismo, puede ser llamado un fin de la naturaleza. En un reloj, una parte sirve de instrumento para el movimiento de las demás, pero una rueda no es la causa eficiente que produzca las otras. [...], menos aún que un reloj produzca otros relojes y utilizara para ello otra materia. De ahí que tampoco reponga por sí mismo las partes que le falten, o remedie las carencias de su primera formación con la ayuda de las otras partes, o se repare a sí mismo cuando se estropee; en cambio todo eso podemos esperarlo de la naturaleza organizada. Un ser organizado no es, por tanto, una mera máquina [...] sino que él posee en sí fuerza configuradora, y tal, por cierto, que la comunica a la materia que aún no la tiene (la organiza), luego una fuerza configuradora que se propaga y engendra, la cual no puede ser explicada solamente mediante la capacidad de movimiento (mediante el mecanismo) ([1790] 1981, pp. 284-285).
\end{abstract}

De este modo, Kant se pregunta a sí mismo cómo fines que no podemos atribuir a la Naturaleza (ya que no asumimos que la Naturaleza posea una inteligencia consciente) van a constituir, o podrían constituir, un tipo especial de causalidad. Este tipo "especial" de causalidad en el que las partes generan el conjunto, y, a su vez el conjunto produce y mantiene a las partes, es circular: los efectos derivan de las causas, pero, al mismo tiempo, las generan. Sin embargo, esta perspectiva abre una brecha entre el mundo biológico y el físico, ya que los organismos no estarían regidos por los principios que se aplican a todas las demás entidades físicas. Y seguramente por esta razón, la visión kantiana de los organismos, profundamente antimecanicista, tuvo un escaso eco en el pensamiento biológico dominante.

Esta situación empezó a cambiar en la segunda mitad del siglo XX, gracias principalmente a la labor de un grupo de biólogos (Maturana, Varela, Ganti, Rosen y Kauffman entre otro). Estos investigadores comenzaron a desarrollar una teoría del organismo inspirada en este punto de vista kantiano, pero tratando de formularla en términos más modernos y científicos. Tomando la organización metabólica como la característica más fundamental de los organismos, estos autores mostraron que la organización constitutiva de los sistemas biológicos da cuenta de un régimen distintivo de causalidad, capaz no sólo de producir y mantener las partes que contribuyen al funcionamiento del sistema como un todo integrado, operativamente distinto, sino también, capaz de promover las condiciones de su propia existencia a través de su interacción con el medio ambiente. Esto es esencialmente lo que llamamos la autonomía biológica.

\section{La idea de autonomía biológica}

En un sentido muy general, la idea de autonomía se refiere a la capacidad de actuar de acuerdo a un conjunto de principios auto-determinados. Una entidad autónoma se rige por sus propias normas. Sin embargo, en biología, el término "autonomía", introducido por Maturana y Varela en la década de 1970, describe las capacidades de auto-producción y mantenimiento de las entidades vivientes. Así pues, en el ámbito biológico, la idea de autonomía se entiende, más que como una forma de acción, como una auto-constitución radical (de ahí que estos autores prefirieran introducir un nuevo término, 
“autopoiesis", que significa autoproducción, para denominar la autonomía biológica en su forma fundamental).

Es importante entender que, en este sentido de auto-producción, el uso del término "autonomía" en Biología constituye la forma más básica de autonomía. Aunque Maturana y Varela (1980) hablaran también genéricamente de autonomía (en el dominio biológico) como "la capacidad de autoafirmación de los sistemas vivos para mantener su identidad a través de la compensación activa de las deformaciones" (p. 135), su concepto de autopoiesis es más fundamental porque expresa el origen de esta capacidad, y por lo tanto, para estos autores, incluso define a lo viviente.

Por consiguiente, para dar una idea de lo que implica el concepto de autonomía en Biología, hay que presentar en primer lugar cómo este concepto se entiende en la teoría de la autopoiesis. La autopoiesis se refiere a la capacidad de auto-producción del metabolismo biológico, haciendo hincapié en su circularidad causal (lo que Maturana y Varela denominan "cierre operacional"). Un sistema autopoiético consiste en un proceso recursivo de producción de componentes que genera su propia frontera física (es decir, un conjunto de componentes que, a través de sus interacciones químicas, generan a ciertos componentes los cuales se ensamblan y "encierran" al sistema, y así lo constituyen como una unidad). A su vez, la frontera física permite que la red de producción de componentes se mantenga, asegurando las concentraciones adecuadas. La red global de producción de componentes establece una dinámica de auto-mantenimiento, que constituye al sistema como una unidad operativa. En resumen, el borde físico y los procesos metabólicos están imbricados en una red de producción cíclica, recurrente y que en conjunto constituyen la identidad del sistema.

\section{Problemas}

Sin embargo, la forma en la que Maturana y Varela concibieron la autonomía biológica básica plantea una serie de problemas. Los dos más importantes son, por un lado, el explícito rechazo a incluir cualquier consideración energético-material en la definición del concepto; y por otro (en buena medida relacionado con el primero), también el rechazo a incluir en la definición la dimensión interactiva. Los autores definen la autonomía en términos muy abstractos: los aspectos materiales y energéticos son considerados como puramente contingente para su realización. Desde esta concepción, lo que importa es la "lógica" recursiva, y por tanto, la autonomía se define en un sentido puramente "internalista", en términos del cierre operacional entre la red de producción y la frontera física. Por tanto, las interacciones con el medio ambiente, aunque física y químicamente (e incluso, termodinámicamente sean necesarias, no entran en la definición-constitución del sistema autónomo. Lo fundamental es el concepto de coherencia interna de la red, la cual, en su plasticidad, podrá mantener (dentro de ciertos márgenes en cada caso) su identidad a pesar de las "perturbaciones" externas. Derivadamente, un sistema autopoiético podrá incluso establecer con su entorno un historial de interacciones exitosas (que Maturana y Varela denominan "acoplamientos estructurales") las cuales son vistas como una continuación de la identidad interna específica de cada sistema autopoiético.

La razón principal por la que esta visión de la autonomía no puede funcionar es que los organismos son organizaciones esencialmente precarias, y lo son precisamente porque están alejadas del equilibrio termodinámico (TD); en consecuencia, sólo "haciendo cosas" (en el entorno) pueden mantenerse. Evidentemente, para "hacer cosas" tienen que poseer una organización, pero el mantenimiento de ésta, a su vez, depende de las acciones que desencadena en su entorno.

Ya en los años noventa, varios autores (Kauffman, Bickhard, Christensen, Hooker y muchos otros) insatisfechos con esta visión, trataron de re-elaborar el concepto de autonomía biológica y plantearla en el marco de la termodinámica (TD). Kauffman (2000) por ejemplo ha definido a los sistemas autónomos como bucles cerrados entre las constricciones que ellos crean y los flujos ordenados de energía que realizan la "función" (y por eso constituyen "trabajo") de generar dichas constricciones. En la misma línea, Bickhard, Hooker y Christensen (Bickhard 2000, Christensen \& Hooker 2000) han definido la autonomía en términos de un conjunto de procesos que se mantienen precariamente alejados del equilibrio TD gracias a su propia acción. En el planteamiento de estos autores es 
fundamental la dimensión interactiva, es decir, la acción del sistema sobre los flujos energéticos y materiales con su entorno, pues es esta acción la que mantiene la identidad, termodinámicamente disipativa, del sistema. ${ }^{1}$

Sin embargo, a pesar de estas diferentes modificaciones, en mi opinión, el concepto de autonomía debe todavía ser desarrollado y revisado. Y ello por dos razones fundamentales: Por un lado, porque desde su origen, la vida ha desarrollado una multitud de organizaciones colectivas cohesivas -pero no necesariamente organísmicas- y por tanto, entidades que podemos considerar como sistemas autónomos de segundo orden. Esta tendencia a la cooperación, a la interdependencia, constituye un reto para el concepto de autonomía (entendida como individualidad organísmica) pues requiere desarrollar una visión del concepto de autonomía que a un tiempo salvaguarde el núcleo conceptual de la individualidad organísmica y al otro dé cuenta de esta capacidad de inter-dependencia y cooperación. Y la otra razón fundamental por la que el concepto de autonomía debe ser todavía revisado es porque, desde el punto de vista diacrónico, la organización de los organismos está causalmente inserta en una historia evolutiva. Desde luego, este hecho es fundamental, porque (solo así se) permite una autocomplejización ilimitada de la autonomía. Pero esto conlleva re-formular el concepto de autonomía biológica poniendo como condición que ésta debe ser formulada de tal manera que permita una autocomplejización ilimitada de sí misma (por ejemplo, que implique una lógica autorreproductiva basada en una memoria genética, aun cuando, en algún sistema particular, de manera circunstancial, esta lógica no sea operativa). ${ }^{2}$

¿Cómo vamos a avanzar en estos dos retos? Para responder al primero de ellos, es necesario ver la autonomía como intrínsecamente interactiva, pues desde esa perspectiva la proliferación de sistemas autónomos va a generar necesariamente un entramado de complementariedades, cuya forma básica es el mundo de las relaciones ecológicas. Este hecho es fundamental porque, junto con el segundo, es lo que posibilita que los sistemas autónomos se hayan mantenido y complejizado (Casado da Rocha 2014). Pero al mismo tiempo requiere mostrar que solo desde la constitución de formas muy cohesivas e integradas de individualidad se pueden establecer esos entramados complejos de cooperación. Para lo segundo, es necesario ver la autonomía como una forma de organización resultado , y capaz, de generar un desarrollo histórico. La autonomía es una propiedad de formas de organización químicas muy complejas, y no habría aparecido, ni se habría mantenido, ni complejizado si los sistemas que la originaron no hubieran desarrollado una capacidad para producir una vinculación inter-generacional a través de la reproducción con herencia. La autonomía biológica debe ser por tanto pensada como una integración de procesos que ocurren a dos escalas temporales diferentes: una, la de los procesos físicoquímicos de los organismos, y otra, más lenta, la de los procesos evolutivos (esta es la base de la famosa distinción de Mayr 1961 entre causas "próximas" e "históricas").

\section{Una visión alternativa de la autonomía}

En las páginas siguientes voy a esbozar algunas ideas para hacer frente a estos retos. Desarrollaré esta parte del trabajo en dos grandes bloques, si bien ambos se derivan de una serie de conceptos fundamentales comunes. El primero de ellos tratará de explicar de qué manera el concepto de autonomía debe ser entendido para ser un instrumento útil en la explicación del complejo entramado fenomenológico de organizaciones "sincrónicas" a escala colectiva de la vida; es decir, para explicar la compleja relación entre lo colectivo y lo individual en sus múltiples aspectos (ecológicos, simbiosis, colonias, organismos multicelulares). El segundo, en cambio, está enfocado a la explicación de la dimensión histórico-evolutiva de la vida; es decir, de qué manera hay que entender la autonomía para

\footnotetext{
${ }^{1}$ El autor de este trabajo (en colaboración con Ruiz Mirazo, Etxeberría, Umerez, Mossio y otros) ha desarrollado desde los 90 una idea de autonomía basada en esta misma línea de pensamiento. Véase, por ejemplo, Ruiz Mirazo y Moreno (2004), Ruiz Mirazo, Peretó y Moreno (2004) y sobre todo, Moreno y Mossio (2015).

2 Como sucede en un organismo estéril. Sin embargo, tal organismo siempre es resultado de un proceso de reproducción, y su organización, en lo esencial, está diseñada dentro de la lógica reproductiva.
} 
explicar esta dimensión, sin duda fundamental, de lo viviente. Y aunque trataré estos dos aspectos por separado, es obvio que en lo esencial, las bases organizativas de uno y otro han de ser las mismas. Así pues, por mor de mayor claridad, comenzaré con la explicación de las nociones básicas comunes, y luego, a partir de esta plataforma conceptual básica, desarrollaré los dos aspectos mencionados separadamente.

\subsection{Autonomía como cierre de constricciones ${ }^{3}$}

Como ya hemos visto, un concepto fundamental sobre el que todos los autores coinciden es que la autonomía está basada en una forma de cierre causal. Pero ¿cuál es el tipo de cierre que permite articular el concepto de autonomía, dotándolo del potencial explicativo que pretendemos? El cierre de procesos químicos que constituye el metabolismo (y por derivación, a los sistemas y organismos multicelulares) no implica solamente un conjunto de reacciones cíclicas. Por el contrario, el tipo de cierre que realizan (y que constituye a) los sistemas biológicos consisten en un tipo específico de dependencia mutua entre un conjunto de entidades materiales que actúan sobre los procesos básicos (i.e., las reacciones químicas) selectivamente. Estas entidades (como las enzimas o las membranas) reciben el nombre de "constricciones". Las constricciones son estructuras macroscópicas que canalizan selectivamente los procesos microscópicos reduciendo sus grados de libertad (es decir, los "ordenan"). Por ejemplo, en una máquina de vapor, el pistón y el cilindro actúan como constricciones sobre el flujo del vapor, ya que canalizan y ordenan el flujo de miles de millones de moléculas de vapor, reduciendo sus grados de libertad. De manera similar, en una célula viva la membrana y las enzimas canalizan selectivamente la dinámica microscópica de los flujos moleculares producidos por las reacciones químicas.

¿Por qué centramos nuestra atención en las constricciones? Porque son las estructuras materiales que mantienen todo el sistema en condiciones alejadas del equilibrio TD. Si no fuera por la acción de las enzimas y la membrana, el conjunto de reacciones evolucionaría hacia el equilibrio TD. Por eso, se dice que en la célula los procesos químicos están "bajo control cinético" (y espacial). Ahora bien, mientras que en los sistemas artificiales las constricciones son estructuras muy estables (y además, fabricadas externamente), en la célula éstas son estructuras altamente inestables y de hecho, son continuamente re-construidas por la organización del sistema. Y este hecho, además, es de capital importancia, porque evita la regresión al infinito que supondría buscar un origen externo a las constricciones (pues si la célula no las fabricara, deberíamos buscar otro sistema que lo hiciera, y a su vez, otro que fabricara a éste, y así sucesivamente). Por lo tanto, la explicación última de por qué están ahí las constricciones es porque ellas mismas producen un conjunto de consecuencias tales que su acción produce en última instancia a las propias constricciones. Un ciclo de constricciones aparece, por consiguiente, cuando un conjunto de constricciones se liga entre sí, en una especie de efecto de refuerzo mutuo, creando un proceso auto-mantenido y de dependencia mutua entre ellas. De esta manera, la acción de cada constricción es canalizar selectivamente las interacciones químicas subyacentes, de forma que el resultado conduce a la producción de otra constricción, y así sucesivamente, hasta que el proceso se cierra de forma recursiva. La única manera de lograr el mantenimiento de las constricciones -que en la célula son estructuras precarias, con vida corta- es por tanto, mediante la creación de una dependencia circular entre ellas (y más concretamente, en el origen de la organización celular, entre las enzimas (o proto-enzimas en su origen) y la membrana.

Es esta circularidad causal -en el ámbito de las constricciones- lo que define la peculiaridad básica de los sistemas biológicos y los diferencia de una manera fundamental de otras formas de circularidad causal que existen en el mundo físico-químico (ciclos geoquímicos, por ejemplo). La idea general más importante que implica este planteamiento es que un conjunto de moléculas es capaz de crear unas estructuras que a su vez imponen unas "reglas adicionales" sobre las leyes físico-químicas que rigen sus procesos básicos. Es decir, que -aunque todavía en un sentido mínimo- la materia se organiza a sí

\footnotetext{
${ }^{3}$ Las ideas de esta sección están desarrolladas más ampliamente en una serie de artículos, principalmente en Mossio y Moreno (2010) y, sobre todo, en Moreno y Mossio (2015).
} 
misma creando sus propias normas ("auto-nomos"). Como vamos a ver a continuación, esta forma de organización a su vez nos va a permitir naturalizar un concepto fundamental del dominio biológico: el concepto de función. Muy brevemente, una constricción en el marco de un cierre de constricciones constituye una función para el sistema, puesto que: a) contribuye al mantenimiento de todo el sistema; b) se genera internamente; c) existe en virtud de lo que hace, es decir, existe debido a sus efectos, y d) actúa diferenciadamente, es decir, el sistema contiene un conjunto diferenciado de constricciones, que hacen contribuciones distinguibles al auto-mantenimiento global del sistema (véase más detalles en Mossio, Saborido \& Moreno 2009, Saborido, Mossio \& Moreno 2011 y Moreno \& Mossio 2015). Por lo tanto, el concepto de autonomía como cierre de constricciones puede naturalizar el concepto de función en términos de la organización actual de un organismo, sin necesidad de recurrir a un proceso histórico de Evolución por Selección Natural, como hacen las Teorías Etiológicas.

Una vez explicado cómo dentro de este enfoque de la autonomía se construye el concepto de función, vamos a analizar el tema de las jerarquías funcionales, y en particular, el tema de las funciones regulatorias. Este asunto es de suma importancia, pues sin la invención de mecanismos regulatorios habría un cuello de botella en el incremento de la complejidad funcional: sin regulación, cuanto más aumenta la complejidad funcional de un sistema, más frágil se hace ante las perturbaciones. Por eso, una idea de autonomía que no admita regulación resultaría incompatible con la evolución.

Las funciones regulatorias son funciones de segundo orden: a diferencia de las funciones de primer orden, que operan constriñendo los flujos TD básicos, las funciones (o "controles") regulatorias operan modulando la acción de las funciones de primer orden. operan en las limitaciones primarias (o constitutivos). Por ejemplo, la acción de una enzima alostérica, que modula una determinada ruta metabólica activando o desactivando la enzima que cataliza ese proceso. Una característica esencial para poder hablar de funciones regulatorias es que éstas operen a escalas temporales diferentes de los procesos que regulan: es decir, las acciones regulatorias, para ser tales, deben estar dinámicamente desacopladas de los procesos regulados. ${ }^{4}$ En segundo lugar, los procesos regulatorios son respuestas específicas a estímulos definidos en las condiciones externas (o internas) del sistema, no son simples respuestas homeostáticas a perturbaciones inespecíficas. La regulación es de suma importancia para permitir la coordinación funcional fiable cuando aumenta la complejidad de la organización (Bich et al. 2015).

Pero el requisito de la regulación implica para la idea de autonomía dos consecuencias fundamentales. La primera, que la organización autónoma biológica debe ser jerárquica, ya que para que pueda hablarse de la existencia de (auto)regulación en el sistema, éste debe poseer al menos dos tipos de procesos dinámicamente desacoplados (pero obviamente funcionalmente conectados). La segunda consecuencia es la necesidad de integración funcional. Un sistema autónomo no es el resultado meramente de la coordinación funcional de diversos sistemas -como ocurre entre los organismos que forman una colonia o entre las aves que forman una bandada-, sino un todo integrado donde las partes están organizadas jerárquicamente según un principio regulatorio global. Volveremos sobre esta idea en las secciones siguientes.

\subsection{Agencialidad ${ }^{5}$}

En la sección 3 adelantamos la idea de que la autonomía es intrínsecamente precaria y sólo puede existir realizando acciones en su entorno; y que, a su vez, estas acciones que mantienen a la organización autónoma, requieren de ésta. Por lo tanto, la autonomía implica dos tipos de procesos relacionados entre sí, y sin embargo, conceptualmente distintos: procesos constitutivos y procesos interactivos. Los primeros son los procesos por el cual un sistema se constituye (desarrollo) y se mantiene (metabolismo). Los segundos son las acciones específicas desencadenadas por el sistema en el entorno, de acuerdo con las condiciones ambientales detectadas, a fin de modificar estas condiciones

\footnotetext{
${ }^{4}$ Un par de reacciones acopladas que realizan un feed-back no constituyen por tanto sensu stricto un proceso regulatorio.

${ }^{5}$ Las ideas contenidas en esta sección están desarrolladas en el capitulo 4 de Moreno y Mossio (2015), Barandiaran y Moreno (2008). Véase también Barandiaran, Di Paolo y Rohde (2009) y Arnellos y Moreno (2015).
} 
para el beneficio del sistema. Por ejemplo, un organismo unicelular puede mover un flagelo en su membrana, lo cual moverá en una determinada dirección al organismo, si detecta condiciones preferibles en dicha dirección.

¿Cuál es la causa u origen de estas acciones? Obviamente, la maquinaria interna del sistema, es decir, por formularlo genéricamente, (una parte de) sus propios procesos constitutivos. En el ejemplo anterior, hay un subsistema que se activa cuando ciertas proteínas de membrana detectan determinados estímulos y finalmente proporcionan ATP para activar el movimiento del flagelo. En otras palabras, son los procesos constitutivos los que "soportan" organizacionalmente las interacciones; pero es que éstas, a su vez, contribuyen a mantener la organización básica: con sus movimientos funcionales, el organismo se desplaza hacia donde hay alimento y huye de donde hay predadores o, simplemente, condiciones desfavorables. Un sistema autónomo, como dijimos, es un sistema "precario", que debe hacer cosas para mantener su identidad: se mantiene -y en última instancia, es constituido- a través de sus acciones. Por lo tanto, un sistema autónomo es necesariamente, un agente. La agencialidad se define pues del modo siguiente: la organización constitutiva de los organismos biológicos ejerce un conjunto de procesos interactivos en su entorno (es decir, impone constricciones sobre los procesos externos) de tal manera que estos procesos contribuyan al mantenimiento continuo de la organización constitutiva del sistema. Recogemos esta idea en lo que hemos denominado como "Principio del cierre entre procesos constitutivos e interactivos" (Arnellos \& Moreno 2015). Los procesos ejercidos sobre el medio ambiente son por tanto funcionales y normativos: modifican las condiciones de contorno del agente de modo que satisfagan un objetivo, que es el mantenimiento de la organización precaria del agente. Si el agente no actúa de una manera específica (es decir, obtener alimentos, evitar a los depredadores, etc.) su identidad -precaria- entraría en un proceso de desintegración.

\subsection{Implicaciones: autonomía como inter-dependencia}

Los agentes autónomos generan relaciones interactivas entre ellos, y a menudo, estas interacciones hacen contribuciones al mantenimiento respectivo. Dado que los agentes autónomos generan relaciones interactivas entre ellos, a menudo las interacciones de unos pueden contribuir al mantenimiento de otros. Y si esta relación es recíproca, estas interacciones mutuas son funcionales, y estos agentes se hacen interdependientes. En realidad, esta situación se ha convertido en regla y los organismos han tejido un conjunto de interdependencias funcionales de todo tipo (ecosistemas, simbiosis, colonias...). Este hecho, lejos de ser un problema para la concepción de la vida como autonomía, es en realidad la consecuencia lógica del concepto de autonomía que hemos desarrollado anteriormente. Si un sistema autónomo es un cierre de constricciones, entonces cualquier proceso que haga una contribución al mantenimiento del sistema se fijará. Cuando en el curso de la evolución, diferentes sistemas autónomos, de forma contingente, interactúan y esta interacción contribuye al automantenimiento de ambos, la interacción se estabilizará, y en muchos casos dará lugar a nuevas formas de vida asociadas. Estas nuevas formas asociadas constituyen a su vez nuevas modalidades colectivas de cierres de constricciones. Deberemos llamarlas "cierre de constricciones de segundo orden", porque están formadas por partes que ya son a su vez cierres de constricciones. Lo interesante es que su asociación les permite mejorar su supervivencia y ocupar nuevos nichos, desarrollar nuevas capacidades interactivas y estas nuevas capacidades interactivas, a su vez, abren la posibilidad de nuevas formas de asociación, y éstas a otras nuevas, y así sucesivamente. Y cuando algunas de estas entidades de segundo orden logran una integración funcional global, pueden generar una nueva forma compuesta (o de “segundo orden") de autonomía (Arnellos, Moreno \& Ruiz Mirazo 2014). Es decir, constituyen lo que denominamos propiamente un organismo multicelular.

Sin embargo, determinar cuándo un sistema colectivo auto-mantenido constituye un individuo autónomo (de segundo orden) en un sentido pleno e integrado plantea muchos retos y dificultades conceptuales, porque las partes que lo constituyen son en sí mismas organismos. Y como muestra la evolución de la vida, los organismos son capaces de generar una gran variedad y complejidad de entidades colectivas, con muy diferentes grados de cohesión e integración. Supongamos que 
analizamos diferentes tipos de sistemas auto-mantenidos colectivos, tales como, por ejemplo, Paramecium Bursaria o Mixotrica Paradoxa, que son unicelulares, Volvox Carteri o Physalia Physalis (conocida popularmente como "fragata portuguesa"), todos ellos multicelulares con cierto grado de cohesión e individualidad global; o incluso, un termitero, que es una organización formada a su vez por organismos multicelulares. En todos estos casos, ¿son las partes más o menos cohesivas que el todo? ¿Hay alguna estructura funcional (o mecanismo) que delimite espacialmente el sistema global? ¿Dónde opera la selección natural, en las partes o en la totalidad? ¿Qué organización asegura el mantenimiento metabólico y la reproducción del sistema global? ¿Cuál es la fuente de la agencialidad -si el sistema colectivo muestra cierta forma de acción global- las partes o la totalidad? ¿Es la organización colectiva la fuente de propiedades nuevas y más complejas? Obviamente, no es fácil contestar a estas cuestiones. Nuestra tesis, sin embargo, es que la idea de autonomía es de nuevo clave para entender la aparición de un verdadero sistema colectivo integrado y poder diferenciar un organismo multicelular de otras formas asociadas con cierto grado de individualidad. La aparición de una forma de organización jerárquica, donde el conjunto de las funciones del sistema están selectivamente organizadas y obedecen a un centro regulatorio es el indicativo fundamental de la autonomía de segundo orden (Ruiz Mirazo \& Moreno 2012, Arnellos, Moreno \& Ruiz Mirazo 2014, Arnellos \& Moreno 2015).

\section{La dimensión histórica de la autonomía}

Como ya hemos explicado, la realización de la autonomía biológica requiere, incluso en su forma celular más simple, unos niveles de complejidad estructural (macromoléculas y vesículas) y organizacional (procesos controlados por constricciones auto-generadas y a su vez, operando en varios niveles) imposible de surgir de forma espontánea. Por eso, los sistemas autónomos sólo han podido aparecer como resultado de un largo proceso histórico necesariamente acumulativo. En este proceso, seguramente el primer paso fue la aparición de proto-células con capacidades reproductivas. La reproducción con algún tipo de herencia estadística ha tenido que ocurrir para generar una vinculación entre las generaciones que sustente un proceso de incremento de complejidad acumulativo. Y una vez que esas proto-células auto-reproductivas albergaran algún tipo mínimo de diversidad funcional, podría comenzar alguna forma de evolución por Selección Natural pre-darwiniana que ayudara a aumentar su complejidad funcional (Arnellos \& Moreno 2012).

Un paso clave en esta evolución debió de ser la incorporación a las proto-células de componentes con capacidades funcionales secuencialmente dependientes, pues ello permitiría dos grandes ventajas: incrementar la especificidad catalítica por un lado, y asegurar una forma de memoria intergeneracional, por otro. A su vez, este hecho implicó un cambio muy significativo, a saber, la vinculación causal entre la nueva forma de organización individual -las organizaciones autónomas de los primitivos organismos, basadas en metabolismos secuencialmente instruidos- y un escenario temporal y espacial mucho más amplio (de procesos "históricos"), que es donde se generan, selectivamente, las secuencias funcionales que van a heredar los organismos individuales.

No vamos a analizar aquí en detalle a través de qué etapas este complejo proceso ha podido desarrollarse (previsiblemente, a través de un "mundo RNA" antes de llegar al actual modo operativo universal de las células, basado en la disociación entre componentes "memoria" (DNA) y componentes funcionales "activos" (proteínas). ${ }^{6}$ Lo que nos importa es comprender qué implica esta forma de organización desde la perspectiva de entender la autonomía biológica que hemos venido desarrollado (para un análisis detallado de esta cuestión, véase Ruiz Mirazo, Umerez \& Moreno 2008).

¿Cuáles son estas implicaciones? La observación fundamental es que nos encontramos ante una forma de organización basada en un tipo de componente -las moléculas de DNA- que, siendo claves para el organismo, sin embargo son operacionalmente inactivas. A primera vista diríamos que los genes -los trozos del DNA que especifican la síntesis de cada proteína- son constricciones plenamente

\footnotetext{
${ }^{6}$ Conservando sin embargo los antiguos RNAs con papeles funcionales claves para la interrelación entre DNAs y proteínas.
} 
funcionales, y lo son precisamente por su rol clave en la síntesis de las enzimas y demás proteínas. Ahora bien, analizando la cuestión más en detalle, esto solo es así con la ayuda de (algunas de) las constricciones funcionales "activas" (las enzimas) cuya síntesis los genes especifican. Por tanto, su papel causal directo como constricciones funcionales es, estrictamente, nulo. Y sin embargo, su papel causal indirecto es fundamental. Esto nos plantea un problema importante, pues es evidente que la formulación que hemos hecho hasta ahora de la autonomía como "cierre de constricciones", incluso en términos de diferentes niveles de constricciones (regulación), estaba basado en la idea de que las constricciones son elementos funcionales "activos". ¿Cómo entender el hecho de que el sistema dependa de unas estructuras funcionales que, para actuar como constricciones, necesitan de otras estructuras funcionales, las cuales son, paradójicamente, el resultado de la "acción" de aquellas?

Pattee (1982) ha explicado este hecho paradójico como un nuevo tipo de cierre, que él ha denominado "cierre semántico". Como este autor argumenta, si los genes tienen un papel causal especial (como "registros" o plantillas "informacionales"), instruyendo la síntesis de las proteínas, es gracias a la actividad organizada de un conjunto de proteínas (y RNAs) que actúan como lo hacen en virtud de su inserción en el cierre de constricciones fundamental que constituye el metabolismo (y que hemos descrito en la sección 4.1.). Pero, por otro lado, a su vez, todas estas constricciones funcionales "activas" (incluyendo muchas de las regulatorias) no podrían existir sin los genes, ${ }^{7}$ y por eso el sistema celular es globalmente un cierre. Pero un cierre de nuevo tipo: un cierre de constricciones funcionales activos (a su vez, incluyendo diferentes niveles regulatorios) y otro, de componentes informacionales pero operacionalmente inactivos, que solo operan causalmente en virtud del primer cierre de constricciones, evolutivamente anterior; y con el resultado de que ambos han generado un bucle interdependiente lo que Hofstadter $(1979,2007)$ ha denominado un "entangled hierarchical loop".

Pero este hecho tiene otra implicación importante. El "cierre semántico" de Pattee, a su vez, requiere una espacial y temporalmente más amplia forma de cierre: durante muchas generaciones, el orden secuencial de estos registros hereditarios (que denominamos genes) pueden sufrir cambios; todos esos cambios (que permiten la reproducción viable de los organismos individuales cuyos metabolismos instruyen) darán lugar a una exploración del espacio secuencial. Esto permite a los organismos individuales reclutar los resultados (es decir, los patrones seleccionados a través de un lento proceso histórico de selección natural). El proceso evolutivo, en el que toda la población y su entorno están involucrados, determina en gran medida los cambios que afectan a las secuencias de los genes. De este modo, los sistemas autónomos genéticamente instruidos pueden consistentemente vincular la dimensión individual de su actividad a una dimensión temporal y espacial progresivamente más amplias. En términos generales, por lo tanto, la autonomía genéticamente instruida implica una forma más amplia de cierre que vincula la autonomía individual a una dimensión histórica y poblacional.

La idea de autonomía biológica fue introducida -recordemos la cita de Varela en la Introducciónen cierto modo en contraposición a la de evolución; o al menos, al predominio de ésta como núcleo explicativo en la Biología. Nosotros hemos tratado aquí, en cambio, de desarrollar un concepto de autonomía biológica complementario de la evolución. Un concepto de autonomía que, por un lado, permita una comprensión de las formas organizacionales en que se sustenta la progresiva aparición de capacidades evolutivas durante el proceso de biogénesis; y por otro, permita también entender cómo estas formas de organización han llegado a dar lugar a la vida como la conocemos, tejiendo un entramado de relaciones causales entre sistemas individuales y un sistema histórico-colectivo. Y lo que hemos tratado de mostrar en esta sección es cómo, en la propia organización de los organismos individuales (unicelulares y multicelulares) esta vinculación con la dimensión histórica y poblacional aparece con toda su importancia.

\footnotetext{
${ }^{7}$ No sólo dependen de los genes para transmitirse inter-generacionalmente, sino para mantener operativa la propia organización metabólica.
} 


\section{Conclusiones}

Así pues, finalmente, ¿por qué importa la autonomía? ¿Cuál es la relevancia de este concepto para la Biología? La autonomía es, en primer lugar, relevante para la comprensión de la especificidad de la vida dentro de una perspectiva más amplia físico-química y termodinámica, pues trata de formularse en términos basados en estas ciencias. La autonomía es, en segundo lugar, relevante para una mejor comprensión del despliegue en complejidad, del fenómeno de la vida, pues, partiendo de términos que se engarzan en las ciencias físico-químicas, al mismo tiempo, trata de fundamentar y explicar de qué manera es posible generar un nuevo ámbito, emergente, de fenómenos, y cómo éstos pueden a su vez generar una ilimitada complejidad.

En segundo lugar, la idea de autonomía es útil porque, convenientemente reformulada, puede ayudar a una mejor comprensión de los fenómenos biológicos, en el sentido de permitirnos descubrir relaciones, muchas veces ocultas, entre diferentes dominios (ecología, fisiología, etología, desarrollo, evolución); y en el sentido de proporcionar una explicación naturalista de conceptos como teleología, función, normatividad, regulación o agencialidad.

Y en tercer lugar, la idea de autonomía también es relevante para repensar y reorientar la investigación científica en Biología, en la medida en que puede contribuir al desarrollo de una teoría más unificada, global e integrada dentro de lo que es hoy el conjunto de las ciencias de la vida. Obviamente, este conjunto de ideas que acabamos de presentar aquí no pretende ser una teoría científica. Sin embargo, sí puede influir y modificar la investigación actual en muy diferentes áreas de la biología (evolución, desarrollo, teoría celular, origen de la vida, ecología, neurología). Y esta influencia se puede evaluar en un futuro cercano, viendo si ha contribuido al progreso e integración de las ciencias de la vida. Este es el propósito de este breve trabajo.

Bibliografía

Arnellos, A. y A. Moreno (2012), "How Functional Differentiation Originated in Prebiotic Evolution”, Ludus Vitalis 20(37): $1-23$.

Arnellos A. y A. Moreno (2015), "Multicellular Agency: An Organizational View”, Biology E⿱ Philosophy 30(3): $333-357$.

Arnellos, A., Moreno, A. y K. Ruiz Mirazo (2014), “Organizational Requirements for Multicellular Autonomy: Insights from a Comparative Case Study”, Biology Eु Philosophy 29(6): 851-584.

Barandiaran, X. y A. Moreno (2008), “Adaptivity: From Metabolism to Behavior”, Adaptive Behavior 16(5): 325-344.

Barandiaran X., Di Paolo, E. y M. Rohde (2009), "Defining Agency. Individuality, Normativity, Asymmetry and Spatio-Temporality in Action”, Journal of Adaptive Behavior 17(5): 367-386.

Bich, A., Mossio, M., Ruiz-Mirazo, K. y A. Moreno (2015), "Biological Regulation: Controlling the System from Within”, Biology Eु Philosophy 31(2): 237-265.

Bickhard, M. (2000), “Autonomy, Function, and Representation. Communication and Cognition”, Artificial Intelligence 17(3-4): 111-131.

Christensen, W. y C. Hooker (2000), "An Interactivist-Constructivist Approach to Intelligence: Self-Directed Anticipative Learning", Philosophical Psychology 13: 5-45.

Casado da Rocha, A. (ed.) (2014), Autonomía con otros, Madrid-México: Plaza y Valdés.

Dobzhansky, T. (1973), "Nothing in Biology Makes Sense Except in the Light of Evolution”, American Biology Teacher 35: $125-129$.

Hofstadter, D. (1979), Gödel, Escher, Bach. An Eternal Golden Braid, New York: Basic Books.

Hofstadter, D. (2007), I Am a Strange Loop, New York: Basic Books. 
Kant ([1790] 1981), Critica del Juicio, Madrid: Espasa-Calpe.

Kauffman, S. (2000), Investigations, Oxford: Oxford University Press.

Maturana, H. y F. Varela (1980), Autopoiesis and Cognition. The Realization of the Living, Dordrecht: Reidel.

Mayr, E. (1961), "Cause and Effect in Biology: Kinds of Causes, Predictability, and Teleology are Viewed by a Practicing Biologist”, Science 134: 1501-1506.

Mossio, M. y A. Moreno (2010), "Organizational Closure in Biological Organisms", History and Philosophy of the Life Sciences 32(2-3): 269-288

Mossio, M., Saborido C. y A. Moreno (2009), “An Organizational Account of Biological Functions”, British Journal for the Philosophy of Science 60: 813-841.

Moreno, A. y M. Mossio (2015), Biological Autonomy. A Philosophical and Theoretical Enquiry, Dordrecht: Springer.

Pattee, H. (1982), "Cell Psychology: An Evolutionary Approach to the Symbol-Matter Problem", Cognition and Brain Theory 4: 325-341.

Ruiz Mirazo, K. y A. Moreno (2004), "Basic Autonomy as a Fundamental Step in the Synthesis of Life", Artificial Life 10(3): 235-259.

Ruiz Mirazo, K., Peretó, J. y A. Moreno (2004), "A Universal Definition of Life: Autonomy and Open-Ended Evolution", Origins of Life and Evolution of the Biosphere 34(3): 323-346.

Ruiz Mirazo, K., Umerez, J. y A. Moreno (2008), “Enabling Conditions for Open-Ended Evolution”, Biology $\mathcal{E}$ Philosophy 23(1): 67-85.

Ruiz Mirazo, K. y A. Moreno (2012), "Autonomy in Evolution: From Minimal to Complex Life”, Synthese 185(1): 21. 52.

Saborido, C., Mossio, M. y A. Moreno (2011), "Biological Organization and Cross-Generation Functions", The British Journal for the Philosophy of Science 62: 583-606.

Varela, F.J. (1979), Principles of Biological Autonomy, New York: Elsevier-North Holland. 